\title{
A Study on the TRIZ Theory-based Innovative Talent
}

\section{Cultivation Mode}

\author{
LI Fu-xing, SUN-JIAN, ZHAN Yuan-yue, SUN Qin-hua \\ Xuzhou institute of technology, Xuzhou Construction Vehicles Appearance and Function Design \\ Research Center, Xuzhou 221008, China \\ E-mail:Saintlyboy@163.com
}

Keywords: TRIZ Theory; Innovative Talent; Innovation Ability; Cultivation Mode; Influencing Factor; Practical Teaching

\begin{abstract}
On the basis of the status quo of college students' innovation education and the society's urgent demand for innovative talents, this paper started by introducing the meaning of innovation education, analyzed the status of college students' innovation ability, and pointed out the co-related influencing factors. Therefore, since TRIZ theory can promote the disciplinary crossing and integration, provide innovative principle for innovations and inventions, put forward pertinent methods and measures for enhancing colleges students' innovation ability and formulate the TRIZ theory-based innovative talent cultivation mode, it will be of great significance for guiding the cultivation of innovative talents if this mode is applied to innovative practice teaching.
\end{abstract}

\section{Introduction}

Innovation is the soul of a nation's progress and inexhaustible driving force for social development. To realize innovation, innovative talents teeming with innovation abilities is a necessity, namely, they are high-quality talents who have a solid theoretical basis, a reasonable ability structure and a healthy, innovative personality, and at the same time, can break the routine with innovative thinking and create new achievements, technologies and methods. The cultivation of innovation ability is rule-based and can be carried out under the guidance of modern education theory, in accordance with the objective and specification of innovative talent cultivation, and by use of innovative curriculum system, management system and evaluation method. According to the idea of TRIZ theory: innovation is not randomly-flashy inspiration, but a general problem-solving law; the law points out the innovative method and can predict the innovation results. By applying this law, people can make innovations proactively[1].

\section{Status Quo of College Students' Innovation Ability}

Nowadays, college students' innovation ability is generally poor, and they have strong dependence on the outside world, but have no subjective initiative spirit to make innovations. For instance, Wang Hanqing et al made a sample survey of college students from two universities in Jiangsu and the survey shows that: the innovation ability of freshmen and seniors indicates no obvious difference. The phenomenon reflected in the finding is worrying. At the same time, it indicates that the college students' innovation ability education is far from enough and has many obvious shortcomings[2].

\subsection{Lack of Subjective Initiative for Innovation}

With the development of online entertainment products, some college students get addicted and cannot fix their mind on innovations; their major at college cannot stimulate their interest in learning, and then students are not willing to take the initiative to make innovations in the field of their major; students have a limited grasp of knowledge, lack the teamwork spirit and, when frustrated in solving problems, also restrain their subjective initiative.

\subsection{Lack of Innovative Thinking Ability}

As college students come into contact with more and more new things, they gradually enrich their imagination. However, the range and depth of their knowledge is lacking, thus their thinking 
mode is single, without divergent thinking. And their thinking of problems are not profound or well-rounded, thus retarding their innovation ability.

\subsection{Lack of Innovative Knowledge and Skill}

Affected by the early exam-oriented education, college students put their emphasis solely on different kinds of examination certifications, but lack the cultivation of their practical ability and innovative technology application ability; in addition, the knowledge students have grasped fail to integrate effectively with different disciplines, and then the contents of different disciplines are disjointed, which fails to keep in line with the historical background-- integrative development of many disciplines[3].

\subsection{Lack of Willpower and Interest in Innovation}

College student are highly sensitive to new things and maintain a skeptical and critical attitude towards old concepts. Their lack of willpower and interest in innovation, however, results in their high dependence on the outside world. Consequently, the innovation process lacks depth and width, unable to re-stimulate the driving force for and interest in innovations.

\section{Influencing Factors}

Exam-oriented Education in the Previous Stage: before students go to colleges and universities, the education mode is exam-oriented and students aim to enter a higher grade. Consequently, students' thinking mode changes from being divergent to being centralized, so that students only seek the only standard answer. In this way, students' divergent thinking is considerably confined, thus seriously affecting students' creativity. And then students' innovation ability at the elementary education stage is relatively weak.

The Loose College Environment: before students enter college, the teaching management is subject to a strict study and rest system, under which students are liable to develop a good study and rest habit and maintain a a good learning state; however, the study and rest environment at colleges is relatively loose. The sudden change from a strict study and rest system to a relatively loose learning environment makes students loosen their strict requirements on themselves, make no attempt to make progress and live a carefree life whole day[4].

Lack of Effective Guidance: the talent cultivation program at colleges serves as the framework document for cultivating students. However, the curriculum setting fails to include teaching contents that center on divergent thinking, inventions, creations, etc.. Moreover, over the long teaching process, the contents in related curriculum fail to get adjusted, and consequently, the teaching contents cannot keep in line with students' demand for knowledge, which cannot effectively guide students' innovation education; as the key part of innovation education, teaching activities, in the teaching process, are carried out in the forms of blackboard-writing and PPT, i.e., a way that just repeats who the book says, which cannot stimulate students' interest in learning or guide students in a heuristic manner; as dominators in innovation education, teachers play a critical role in cultivating innovation talents. Some students, however, are content with the status quo and lack the impetus to improve their innovation ability, thus greatly weakening their role in cultivating innovative talents.

\section{TRIZ Innovation Theory Outline}

As psychologist Alexander Naumovich Luke holds, the creativity potential is something intrinsic that everyone has and the key is to dig out and develop it. This indicates that creativity can be acquired through the cultivation of innovation education. Innovation education mainly focuses on the knowledge structure essential for innovation ability, which includes: basic knowledge, professional knowledge, instrumental knowledge and comprehensive knowledge, categories in total. And the TRIZ innovation theory belongs to instrumental knowledge in innovation education.

\subsection{System Composition of TRIZ Theory}

TRIZ, the abbreviation in Russian for “Teoriya Resheniya Izobreatatelskikh Zadatch" , is the theory system formed through the analysis of nearly 2.5 million high-level patents for invention 
worldwide and integration of the theories and rules of multi-disciplinary fields made by the research institution which was led by Altshuller, a former Soviet Union expert. With dialectics, system theory and epistemology as philosophical guidance, the analytic research results of natural science, system science and noetic science as the foundation, and technical system evolution rule as the theoretical basic and core concept, TRIZ theory system includes all kinds of analytic methods, solution tools and algorithm flow that are needed for solving engineering conflict problems and complicated inventive problems.

\subsection{TRIZ Theory-based Innovation Process}

TRIZ innovation theory possesses multi-disciplinary intersectionality and provides solution for inventions and innovations, so that it becomes a system theory and tool for discovering and solving problems, which can be reflected specifically in that:

(1) Launch of TRIZ Theory-based Innovations .The launch of TRIZ theory-based innovations is on the basis of the general law of discovering and solving problems, namely, firstly summarizing special problems into general problems of TRIZ, then applying the general innovation principle and algorithm of TRIZ to find the standard solution, and deducing a general solution to special problems, so as to form a set of scientific, normative innovative thinking, as seen in Fig. 1.

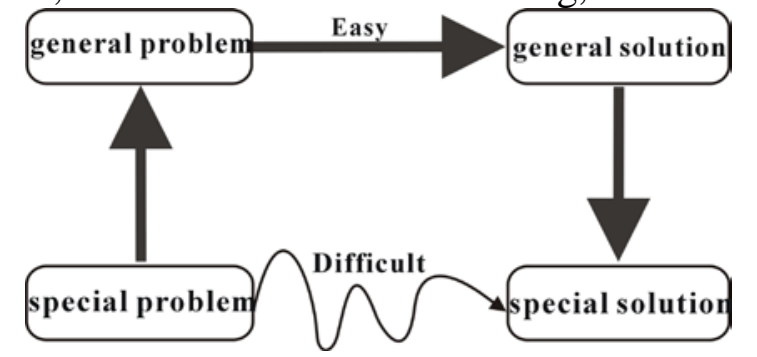

Fig. 1. Basic Thinking for Innovative Solution of TRIZ

(2)TRIZ Theory-based Thinking Diverging. The transformation of general problem into standard problem of TRIZ is just the first step to accelerate innovations. By applying the conflict resolution matrix composed of 39 engineering parameters and 40 pieces of inventive principles, the innovative principle can be modularized. And then, by utilizing inventive principle to guide the direction of innovative thinking, it will further break the thinking set, expand the dimension of thinking, and promote the constant emerging of innovative thinking.

(3) TRIZ Theory-based Inspiration Iteration. Inspiration emerges repeatedly along with different stages of innovative thinking: at the beginning stage of inspiration, the direction will be readjusted; new inspiration will arise at the formation stage, so the solution problem of TRIZ is a process of repeated iteration. And the repeated iteration of TRIZ-based innovative thinking reflects the demand for the formation of inspiration. Moreover, with the introduction of conflict matrix and inventive principle, it will boost the innovative diverging of thinking.

(4) TRIZ Theory-based Formation. The TRIZ theory-based innovative method realizes a highly comprehensive summary of innovation process: by building a stimulating environment for innovative thinking, setting its conversion condition, standardizing the process of innovative activities and applying the invention-creation principle, it will help to carry out the control and prediction of innovative thinking. In addition, by adding on a pre-processing module for handling new problems and a post-processing module generated from innovative plans, a new innovative system frame model can be established, as seen in Fig. 2. 


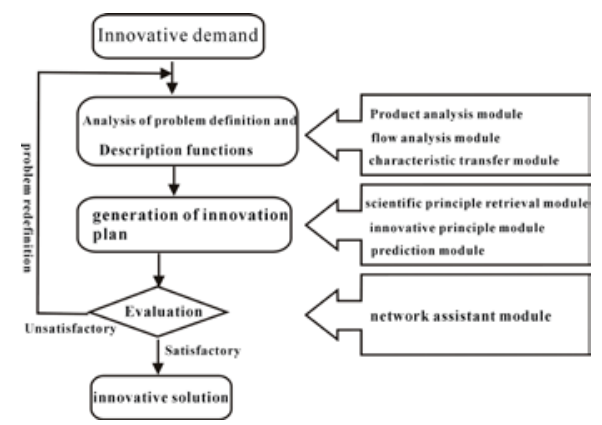

Fig. 2. Comprehensive Framework for TRIZ-based Innovative System

\section{TRIZ Theory-based Cultivation Mode}

\subsection{School dominates the innovation management system}

The management system and talent cultivation mode of traditional higher education tend to be unified, which is very difficult to cultivate innovative talents of distinct personalities. Teresa Amabile, an American psychologist, points out: since there are too many authoritative education pressure and restrictions, such as external evaluation, supervision and reward, students lack independence, which will greatly restrict their innovation development. According to the system theory philosophical thinking of TRIZ theory, colleges and universities shall design the teaching management system from the top level, namely, they should develop a concept of cultivating innovative talents, establish a diversified quality view centering on personalized cultivation, so as to build a safe and free psychological state that facilitates students' innovative activities, and promote the healthy development of their innovation personality; In response to the problems in the major setup curriculum system, colleges and universities shall, based on the reform goal of "Consolidating Foundation, Widening Major Orientation, Weakening Major Difference and Intensifying Curriculum”, combine similar majors to constitute a new curriculum system, and strengthen the freedom of selecting courses among different disciplines, majors and schools, so as to reflect the concept of TRIZ theory, multi-disciplinary crossing and integration. With the integrative development of knowledge of different disciplines, students can have innovative thinking ability that covers many disciplines and perspectives[5].

\subsection{Teacher is the key of innovation education}

In the process of cultivating innovative talents, colleges and universities should pay attention to the cultivation and improvement of teachers' innovation ability. Teachers should take TRIZ innovation knowledge and practical ability training, so as to tap their potential for innovations. Moreover, teachers should be provided with a platform for them to bring their talents into play and make innovations independently. In this way, while improving their own innovation level, teachers can guide students to enhance their abilities to find and solve problems in a better manner. Einstein proposed: discovering the problem and elaborating it systematically may be more important than getting the answer. Discovering the problem is the starting of innovation activities. Teachers should focus on guiding students to think about problems and using the 40 pieces of inventive principles of TRIZ to guide students to study problems. In this way, in the process of solving problems, teachers can help students grasp the innovative method, so as to improve their practical innovation ability.

\subsection{Students are the carriers of innovation education}

In 1950s, many famous colleges in America opened some courses, such as creativity development, and so far, there are more than 50 creative study research institutes; after introducing the creativity study curriculum system from America in 1950s, Japan determined it as its strategic guarantee for its entry into $21^{\text {st }}$ century. Therefore, colleges in China can learn from the overseas experience, open courses that focus on cultivating innovation ability, such as creative study and TRIZ innovation method, and make TRIZ innovation theory an optional course; the academic lectures will integrate TRIZ innovation theory into professional teaching; propagandize the innovation education by applying TRIZ innovation theory to related design competition. 


\subsection{Evaluation incentive mechanism is the guarantee of innovation}

An objective, reasonable evaluation and incentive mechanism is the system guarantee for cultivating students' innovation ability. With regard to teachers' performance appraisal, colleges, in addition to such quantitative evaluation factors as topic and dissertation, should put weight on teachers' role in students' innovation education; teachers should establish a set of comprehensive evaluation system, which should incorporate students' theoretical score and students' abilities to discover and solve problems; besides, a pertinent incentive mechanism should be established for students' innovation activities, such as scholarship, practical innovation fund, practical innovation credit, quality development credit and other reward mechanisms, so as to help and guarantee students to carry out innovation activities.

\section{Conclusion}

The cultivation of innovative talents is a systematic project. As the cradle for cultivating innovative talents, colleges should innovate the teaching management mode and build a good innovation-beneficial environment for both students and teachers. As the key part of innovation education, teachers can guide and cultivate innovative talents in a better manner only when they are applying TRIZ theory to strengthen their innovation ability construction. Since the concept of TRIZ innovation theory is characterized by multi-disciplinary crossing and integrative development, college students should have a good grasp of well-rounded knowledge, so as to benefit the innovative thinking diverging and contribute to innovative achievements.

\section{References}

[1]. Hongyan Guan,Fengyu Yang,Qilei Wang. Study on evaluation index system of rubber materials for sealing, J. Materials and Design. 32(2011) 2404-2412.

[2]. Poirson Emilie,Petiot Jean- Franois,Richard Florent. Amethod for perceptual evaluation of products by naive subjects: Application to car engine sounds, J.International Journal of industrial ergonomics. 40(2010) 504-516.

[3]. Lin Chyunchau,Luh dingbang. A vision- oriented approach for innovative product design [J]. Advanced Engineering Informatics, 23(2009) 191-200.

[4]. TENG Jia-hua. The Design of Product Image Based on Brand Strategy[J].Journal of Shandong University of Technology,2007(1):99-101 .

[5]. HU Jie. Multimedia Creative Art[J].Beijing Journal of University of the Arts,2008,19(4):78-81 